\title{
Aberrant promoter methylation of PCDH10 as a potential diagnostic and prognostic biomarker for patients with breast cancer
}

\author{
WENTAO LIU, JIN WU, GUANGYUE SHI, XIAOLONG YUE, DAN LIU and QINGYUAN ZHANG
}

Department of Medical Oncology, Harbin Medical University Cancer Hospital, Harbin, Heilongjiang 150081, P.R. China

Received January 21, 2018; Accepted June 7, 2018

DOI: $10.3892 / \mathrm{ol} .2018 .9214$

\begin{abstract}
Protocadherin-10 (PCDH10) is a tumor suppressor gene. Its expression level is downregulated by promoter methylation in certain types of human tumors. The aim of the present study was to examine the expression level and promoter methylation status of PCDH10 in breast cancer cells and to evaluate the association of PCDH10 methylation and tumor progression and prognosis. MethyLight was used to detect the methylation status of PCDH10 in breast cancer tissues and healthy breast tissues. Reverse transcription-quantitative polymerase chain reaction was used to assess the mRNA expression level of PCDH10, as well as to evaluate the association between PCDH10 methylation and clinicopathological features, along with patients' overall survival (OS). PCDH10 5'-C-phosphate-G-3' (CpG) methylated sites were identified in tumor tissues and matched healthy tissues $(n=392)$. Tumor tissues and matched healthy tissues exhibited identifiable PCR results, with PCDH10 gene promoter methylation identified in ductal carcinoma in situ $(66 \%)$, invasive ductal carcinoma $(82 \%)$, invasive ductal carcinoma with lymph node metastasis $(85.32 \%)$ and hereditary breast cancer tissues $(72.37 \%)$. PCDH10 mRNA expression was significantly decreased in breast cancer tissues compared with healthy breast tissues $(\mathrm{P}=0.032)$. PCDH10 methylation was associated with tumor size $(\mathrm{P}=0.004)$, but not associated with other clinical factors. Survival analysis revealed that the patients exhibiting methylated-PCDH10 had significantly poorer OS times than patients exhibiting unmethylated-PCDH10 $(\mathrm{P}<0.0001)$. Receiver operating characteristic analysis indicated a sensitivity of $75 \%$, a specificity of $62.5 \%$, and an area under the curve of 0.682 for PCDH10. Additionally, the results of the present study indicated that PCDH10 methylation status may be a useful diagnostic and prognostic evaluation biomarker for
\end{abstract}

Correspondence to: Professor Qingyuan Zhang, Department of Medical Oncology, Harbin Medical University Cancer Hospital, 150 Haping Road, Harbin, Heilongjiang 150081, P.R. China

E-mail: qingyuanzh01@sina.com

Key words: protocadherin-10, methylation, breast cancer, overall survival, diagnosis, prognosis breast cancer. The results suggested that PCDH10 methylation is a common occurrence in primary breast cancer and is associated with poor survival rates among patients with breast cancer.

\section{Introduction}

Breast cancer is a variable and complex disease, and is a leading causes of mortality (1). In the United States 23,234 female fatalities are expected to occur due to invasive breast cancer and 39,620 novel cases of invasive breast cancer are expected to be diagnosed in the next decade (2). In the United States, it is expected that $\sim 12.5 \%$ of women will be diagnosed with breast cancer in their lifetime (2). Breast cancer cases in China accounted for $12.2 \%$ of global cases in 2008 (3). Data from the Human Genome Project and the International HapMap Project have enabled geneticists to study polygenic traits and diseases by genome-wide association study (GWAS) (4). An investigation of the genetic basis of common diseases is possible by testing for variants that are significantly associated with cases of disease over controls in a population. GWAS is widely used in genetic epidemiology, resulting in $>1,600$ studies published and reports of $>11,000$ single nucleotide polymorphisms (SNPs) associated with hundreds of different diseases and traits (5). When interpreting GWAS results, it is often difficult to identify the functional variant(s) underlying an association (5). For example, according to GWAS, 93\% of SNPs associated with human phenotypes are located outside of protein-coding regions (6). This emphasizes the requirement for a method of annotation of the vast non-coding sequence in the human genome.

Epigenetic maps serve an important role in identifying specific functional variations that cause or contribute to a number of diseases. Previous studies have reported that epigenetic abnormalities may serve an important role in the initial stages of a number of cancer types, including colorectal cancer and prostate cancer $(7,8)$. Methylation of one allele has been indicated to affect gene activation mutations on the opposite allele (9). The normal genome commonly contains DNA methylation of 70-80\% of all 5'-C-phosphate-G-3' (CpG) dinucleotides (10). It has been hypothesized that this type of DNA methylation prevents the inappropriate transcription of repetitive sequences (7) and maintains chromosomal stability (11). The remaining $\mathrm{CpGs}$ are grouped within short 
DNA regions (0.2-1.0 kb in length) termed ' $\mathrm{CpG}$ islands' (CGIs). Human genes possess $40 \sim 50 \%$ of CGIs in or near the promoter and/or the first exon, whereas a lack of methylation exists in normal somatic cells (10). Alterations in the methylation status of DNA are the most frequent molecular changes observed in various types of cancer (12). Cancer studies focusing on genes with hypermethylated promoter CGIs have revealed unique profiles of hypermethylation that define each neoplasia (13-15). Therefore, DNA methylation may serve as an effective biomarker for cancer as it has been indicated to be associated with tissue-specific gene silencing (13). For instance, hypermethylation of the glutathione S-transferase Pi-1 (GSTP1) gene promoter has been reported to occur in $80-90 \%$ of patients with prostate cancer and is almost undetectable in prostate tissues. Due to this high specificity, it is used as a diagnostic biomarker $(12,16,17)$.

Numerous studies have used methylation patterns as diagnostic and prognostic biomarkers for breast cancer (18). Protocadherin (PCDH)-10 is a member of the PCDH family and is located on the human chromosome 4 q28.3. Protein expression of PCDH has been predominantly identified in the nervous system, serving an important role in signal transduction. PCDH10 promotes cell-cell adhesion via $\mathrm{Ca}^{2+}$ in tissue morphogenetic processes, and apoptosis by upregulating Fas cell surface death receptor, Caspase 8 , Jun proto-oncogene, AP-1 transcription factor subunit, Cyclin dependent kinase inhibitor 1A and HIV-1 Tat interactive protein 2 (19-21). Evidence suggests that members of the PCDH family can inhibit the occurrence and progression of multiple carcinomas. Previous studies have characterized PCDH10 expression downregulation by promoter methylation, and its role as a tumor suppressor gene in the alimentary system and the other carcinomas (22-24). However, to the best of our knowledge, a limited number of studies, have been conducted on PCDH10 expression in breast cancer $(25,26)$. The expression, methylation status, biological function and clinical application of PCDH10 have yet to be determined.

The aim of the present study was to investigate a novel methylation-based diagnostic tool for breast cancer and to resolve the difficulties associated with the implementation of methylation genes as biomarkers. It was demonstrated that PCDH10 could be an effective prognostic biomarker for patients with various types of breast cancer, including ductal carcinoma in situ (DCIS), invasive ductal carcinoma (IDC) and invasive ductal carcinoma plus lymph-metastasis (IDC-L). The changes in methylation status of sporadic breast cancer and hereditary breast cancer $(\mathrm{HpBC})$ were examined, along with overall survival (OS) rate of patients and the association between PCDH10 methylation and clinicopathological features.

\section{Materials and methods}

Patients and sample collection. A total of 392 samples of flash-frozen cancerous and paired healthy breast tissues $(\geq 5 \mathrm{~cm}$ distant from the tumor tissue) were collected from patients with breast cancer, who underwent mastectomy at the Harbin Medical University Cancer Hospital (Heilongjiang, China) between May 2009 and October 2012. Serum samples (1 ml) were obtained from 300 patients $(47 \pm 18$ years old) with breast cancer, as well as from healthy subjects ( $45 \pm 12$ years old) at the Second Affiliated Hospital of Harbin Medical University (Heilongjiang, China) between May 2009 and October 2012. The breast cancer patients with other diseases were excluded from this study according to clinical detection. The healthy subjects were from patients who received physical examination and were identified as healthy. The types of benign breast diseases included fibroadenoma, desmoid tumors, benign phyllodes tumors, mastopathy, papilloma, duct ectasia and hamartoma. The healthy serum sample $(n=300)$ was acquired from the Affiliated Tumor Prevention and Treatment Institution of the Harbin Medical University (Heilongjiang, China) between May 2009 and October 2012. All patients provided written informed consent for tissue and serum collection, in consistence with regulations of the institutional review board of the Harbin Medical University (Heilongjiang, China). The present study was completed in compliance with the Declaration of Helsinki and was approved by the ethics committee of the Harbin Medical University (Heilongjiang, China).

Immunohistochemistry and molecular subtypes. Tissue sections $(8 \mu \mathrm{m})$ were obtained from breast tissues and stored at $-25^{\circ} \mathrm{C}$. These sections were stained with $10 \%$ hematoxylin for $5 \mathrm{~min}$ and $0.5 \%$ eosin for $1 \mathrm{~min}$ at room temperature, and then were examined by two independent pathologists from Harbin Medical University Cancer Hospital (Harbin, China), who were blind to the study, to ensure the integrity of the tumor sample (tumor content $>70 \%$ ), and to verify that healthy tissue blocks contained no tumor cells under light microscopy at x100 and x400 magnifications. Malignant samples were categorized into four groups based on histopathology: i) DCIS; ii) IDC; iii) IDC-L; or iv) $\mathrm{HpBC}$, included patients with a first-degree relative with breast cancer, patients with bilateral breast tumors, and <35-year-old patients with early-onset breast cancer (27-31).

The estrogen receptor (ER) mouse monoclonal antibody was obtained from Ventana Medical Systems, Inc. (1:200 dilution; cat. no. 760-2596; Tucson, AZ, USA) and progesterone receptor (PR) mouse monoclonal antibody from Dako (1:200 dilution; cat. no. M3569; Agilent Technologies, Inc., Santa Clara, CA, USA). The sections were incubated with antibodies at $4^{\circ} \mathrm{C}$ overnight. The bound antibodies were detected using peroxidase-conjugated goat anti-mouse $\mathrm{IgG}$ (ready-to-use secondary antibody; cat.no. TA130004; OriGene Technologies, Inc., Beijing, China) at $37^{\circ} \mathrm{C}$ for $2 \mathrm{~h}$, and the final staining was completed with DAB (OriGene Technologies, Inc.) at room temperature for $3 \mathrm{~min}$. Nuclear labeling revealed that $>1 \%$ of cells were ER- or PR-positive (32). Human epidermal growth factor receptor 2 (HER-2) immunohistochemistry was performed using the DAKO Herceptest kit (Agilent Technologies, Inc.), according to the manufacturer's protocol. Cases were scored according to the number of positive cells as follows: 0 (negative, $<5 \%$ ); $1+$ (weak positive $6-25 \%$ ); $2+$ (positive, 26-50\%); and $3+$ (strong positive, $>50 \%$ ). Fluorescence in situ hybridization analysis for HER-2 amplification was performed for all samples with a score of 2+(equivocal) using the Path Vision kit (Abbott Pharmaceutical Co., Ltd., Lake Bluff, IL, USA), according to manufacturer's protocol. Samples with a $3+$ IHC score or a HER-2 fluorescence in situ hybridization 
amplification ratio $>2.2$ were considered to be HER-2-positive. Samples were divided into one of four categories, according to the accepted and previously validated IHC surrogate profiles of breast cancer (33). Mouse monoclonal antibody P53 (1:100 dilution; cat. no. 760-2542) and Ki-67 (1:100 dilution; cat. no. M7240) antibodies were obtained for nuclear labeling from Ventana Medical Systems, Inc. The incubation process and secondary antibody was identical to that aforementioned. For P53, a labeling score of $>30 \%$ was regarded as aberrant overexpression, which has been previously associated with p53 mutation (34). A cut-off point of 13\% Ki67 expression was used to categorize high- or low-proliferation tumors (35). Luminal tumors were categorized as immunoreactive for ER and/or PR, negative for HER-2 expression or exhibiting low proliferation. ER+ and/or PR+ tissues that were also HER-2+ and/or exhibiting high proliferation were considered to be luminal B tumors. HER-2 subtypes were defined as ER-, PR-, and HER-2+. Based on published criteria, all basal-like cases were considered to have a triple-negative phenotype (ER-/PR-/HER-2-).

DNA extraction. Genomic DNA was extracted from the fresh-frozen primary breast tumor tissues and the matched healthy breast tissues. Samples were pre-treated with $20 \mathrm{mg} / \mathrm{ml}$ proteinase K (Promega Corporation, Madison, WI, USA) at $55^{\circ} \mathrm{C}$ overnight. DNA was extracted using the AxyPrep ${ }^{\mathrm{TM}}$ Multisource Genomic DNA Miniprep kit (Axygen; Corning Incorporated, Corning, NY, USA), according to manufacturer's protocol, and $\sim 5 \mathrm{ml}$ of peripheral blood was collected prior to the physical examination or surgery. All samples were analyzed in the laboratory within $4 \mathrm{~h}$. Circulating free DNA was obtained from $1 \mathrm{ml}$ of serum using the QIAamp UltraSens Virus kit (cat. no. 53706; Qiagen GmbH, Hilden, Germany).

Bisulfite conversion and MethyLight assay by quantitative polymerase chain reaction ( $q P C R)$. The bisulfite conversion of genomic DNA and MethyLight assay was performed using the EZ DNA Methylation kit (Zymo Research Corp., Irvine, CA, USA), according to the manufacture's protocol. For each bisulfite sequencing PCR (BSP) reaction, the PCR mixture included $1.5 \mathrm{mM} \mathrm{MgCl}_{2}, 200 \mu \mathrm{M}$ dNTP, $1 \mu \mathrm{M}$ of forward and reverse primers (sequences in Table I), 2.5 units of Platinum Taq (Invitrogen; Thermo Fisher Scientific, Inc., Waltham, MA, USA) and 1x Platinum Taq buffer to achieve a final reaction volume of $50 \mu \mathrm{l}$. The detailed method was described in a previous study (36). The PCR products were extracted using a $1 \%$ agarose gel, ligated into the pGEM-T vector (Promega Corporation). The proportion of PCR products and the conversion of Escherichia coli (strain DH5a) was conducted according to standardized procedures. Blue-white screening was used to select a minimum of 10 positive bacterial clones, from which plasmid DNA was isolated using a QIAprep Spin Miniprep kit (Qiagen, Inc., Valencia, CA, USA), according the to the manufacture's protocol. Clones were screened by digesting $1 \mu \mathrm{g}$ of plasmid DNA with BstZI (Promega Corporation) and 1\% agarose gel electrophoresis was performed to confirm the insert and plasmid size as reported previously (37). Positive clones were sequenced by Invitrogen (Thermo Fisher Scientific, Inc.).
Table I. The sequences of probes and primers used polymerase chain reaction and methylation analysis.

Primer Sequence

$\begin{array}{ll}\begin{array}{l}\text { Methylation-specific primers } \\ \text { Forward }\end{array} & \\ & \text { 5'-TCGTTAAATAGATACGT } \\ \text { Reverse } & \text { TACGC-3' } \\ & \text { 5'-TAAAAACTAAAAACTT } \\ \text { TaqMan MGB probe } & \text { TCCGCG-3' } \\ & \text { 5'-TGGTTAAGGGTTCGGT } \\ \text { Globin reference primers } & \\ \text { Forward } & \text { 5'-AGGTAGAAAAGGAGAA } \\ & \text { TGAAGATAAA-3' } \\ \text { Reverse } & \text { 5'-CTTTCCACTCTTTTCTC } \\ & \text { ATTCTCTC-3' } \\ \text { TaqMan MGB probe } & \text { 5'-AGGAGGATAAGGAAGA } \\ & \text { GGGGAAATAGG-3' }\end{array}$

The probable promoter $\mathrm{CpG}$ island methylated sites were selected to design probes for the PCDH10 gene, in accordance with the results of BSP sequencing. CpG methylation of the PCDH10 gene was detected using methylation-specific primers (Table I) and the TaqMan ${ }^{\circledR}$ MGB-based probe fluorescence real-time qPCR kit (Applied Biosystems; Thermo Fisher Scientific, Inc.), according to the manufacturer's protocol. TaqMan ${ }^{\circledR}$ MGB qPCR was performed with primers specific to the bisulfite-converted methylated sequences of particular loci, as well as with globin reference primers and TaqMan ${ }^{\circledR}$ MGB probes (Table I). TaqMan MGB probes increased assay specificity and facilitated flexible analysis due to their small size. The thermocycling conditions were as follows: Denaturation at $96^{\circ} \mathrm{C}$ for $5 \mathrm{~min} ; 35$ cycles of amplification at $95^{\circ} \mathrm{C}$ for $10 \mathrm{sec} / \mathrm{cycle}$; and then $60^{\circ} \mathrm{C}$ for $30 \mathrm{sec}$. The quantification of the methylation rate (\%) at a promoter was calculated using the $2^{-\triangle \Delta C \mathrm{Cq}}$ method (38). All samples were assayed in duplicate, to confirm the accuracy of the $2^{-\Delta \Delta C q}$ method and the amplification efficiency. Globin was analyzed using serial dilutions of DNA with a 100 -fold range and gene-specific primers for each gene and globin (Table I). The $\Delta$ Cq value $[\mathrm{Cq}$ (target gene)-Cq (reference gene)] was obtained for each DNA dilution and log DNA dilution vs. $\Delta \mathrm{Cq}$ was plotted.

MethyLight is a high-throughput assay for DNA methylation based on real time qPCR. MethyLight requires only minute amounts of modest quality DNA, making it clinically applicable and compatible for use with small biopsies and paraffin-embedded tissues $(39,40)$. Researchers have used percentage of methylated reference (PMR) to evaluate positive methylation. However, the cut-off value of PMR using MethyLight has been reported to vary among studies (41-44). This may be a result of not including matched normal tissue, but only Sss I-treated human peripheral white-blood-cell DNA from the same patient or from healthy subjects as a control. This method of comparison cannot accurately reflect the number of positive methylation cases, as methylation modification is influenced by many factor, including lifestyle, environmental 
exposures, ethnicity, age and tissue heterogeneity $(40,45)$. The present study used breast cancer tissue and matched healthy breast tissue and methylation percentage of a particular area was assessed using the $2^{-\Delta \Delta \mathrm{Cq}}$ method. A value $\geq 1.5$ (allelic gene methylation) was considered to be positive. MethyLight was also used to determine the methylation frequency of serum DNA $(46,47)$.

Statistical analysis. The levels of methylation and mRNA expression were analyzed using Fisher's exact test and Kruskal-Wallis test. Receiver operating characteristic (ROC) curve analysis, Mann-Whitney U test, Kaplan-Meier survival curves and Cox proportional hazards regression model were used to assess prognostic associations. All tests were performed using SPSS 17.0 (SPSS, Inc., Chicago, IL, USA). $\mathrm{P}<0.05$ was considered to indicate a statistically significant difference.

\section{Results}

Epigenetic identification of the PCDH1O CGI as a hypermethylated sequence in breast cancer. Using bioinformatics analysis to identify DNA fragments $(n=31)$ of the PCDH family, the proximal promoter and exon 1 of the PCDH10 gene were located in $4 \mathrm{q} 28.3$ (48). The PCDH10 gene promoter region comprises two classic CpG islands: CGI-1, -2133 to -854 bp from the transcription start site (TSS), and CGI-2, +367 to +1972 bp from the TSS (Accession no. NM_032961.1). PCDH10 gene promoters in tumor tissue were prescreened and matched with healthy tissues from 6 patients with breast cancer to detect the presence of aberrant methylation targets and to design TaqMan ${ }^{\circledR}$ MGB detection probes, in order to investigate methylation status. Following comparison of the methylation frequency between breast cancer tissues and matched healthy breast tissues, it was determined that PCDH10 gene methylation was significantly increased in breast cancer. The $\mathrm{CpG}$ site analysis demonstrated that the PCDH10 promoter is a typical CGI (Fig. 1) (49).

Prevalence of PCDH10 methylation and mRNA expression in breast cancer tissues. PCDH10 displayed widespread methylation of the aberrant promoter $\mathrm{CpG}$ island. The frequency of PCDH10 methylation significantly increased with disease progression from in situ to invasive cancer. However, no significant difference in methylation was observed between IDC and IDC-L ( $\mathrm{P}<0.05$; Fig. 2). The results of methylation frequency analysis for PCDH10 are indicated in Table II. There was no significant difference between the frequency of PCDH10 gene methylation in sporadic breast cancer tissues and HpBC tissues ( $\mathrm{P}>0.05)$. PCDH10 mRNA expression in breast cancer tissues and paired healthy breast tissues was calculated using the $2^{-\Delta \Delta \mathrm{Cq}}$ method (38). PCDH10 mRNA expression was indicated to be significantly decreased in breast cancer tissues, compared with matched healthy breast tissues, according to qPCR results $(\mathrm{P}=0.0032$; Fig. 3).

Association of PCDH10 methylation with clinicopathological characteristics and breast cancer prognosis. The association between PCDH10 methylation and various clinicopathological features was also examined (Table III). PCDH10 methylation was significantly associated with tumor size $(\mathrm{P}=0.004)$. In
Table II. Frequency of PCDH10 methylation in patients with sporadic and hereditary breast cancer.

\begin{tabular}{lllll}
\hline & \multicolumn{4}{c}{$\begin{array}{c}\text { Breast cancer } \\
\text { tissue methylation frequency }(\%)\end{array}$} \\
\cline { 2 - 4 } Methylated gene & DCIS & IDC & IDC-L & HpBC $(\mathrm{n}=96)$ \\
\cline { 2 - 5 } PCDH10 & 66 & 82 & 85.32 & 72.37 \\
\hline
\end{tabular}

PCDH10, Protocadherin-10; DCIS, ductal carcinoma in situ; IDC, invasive ductal carcinoma; IDC-L, invasive ductal carcinoma plus lymph-metastasis; n, number; $\mathrm{HpBC}$, hereditary breast cancer.

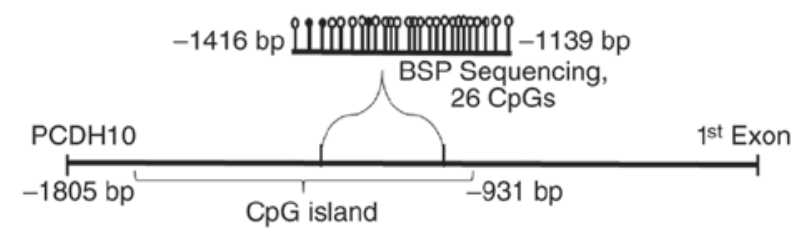

Figure 1. CpG site analysis of the PCDH10 promoter. $\mathrm{CpG}$, 5'-C-phosphate-G-3'; PCDH10, Protocadherin-10.

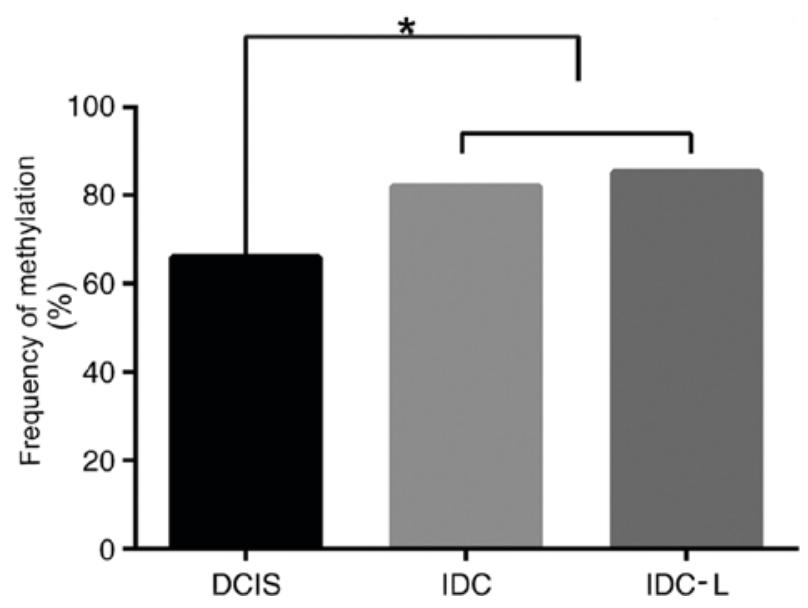

Figure 2. Frequency of PCDH10 methylation in DCIS, IDC and IDC-L tissues. PCDH10, Protocadherin-10; DCIS, ductal carcinoma in situ; IDC, invasive ductal carcinoma; IDC-L, invasive ductal carcinoma plus lymph-metastasis. ${ }^{*} \mathrm{P}<0.05$.

the tumor size $\geq 2 \mathrm{~cm}$ group, the rate of PCDH10 methylation (76.1\%) was significantly increased compared with unmethylated PCDH10 (56.6\%) $(\mathrm{P}=0.004)$. However, no association was observed between PCDH10 methylation and other clinicopathological factors (Fig. 4). Patients exhibiting methylated PCDH10 had significantly lower OS times $(\mathrm{P}<0.0001$, log-rank test) compared with patients exhibiting unmethylated PCDH10. In the Cox proportional hazards regression model, univariate and multivariate survival analyses were applied to assess the association between PCDH10 methylation and clinicopathological features. Univariate analyses of OS rate demonstrated that tumor size $(\mathrm{P}<0.001)$, lymph node metastasis $(\mathrm{LNM})(\mathrm{P}<0.001)$, ER $(\mathrm{P}=0.023)$ and $\mathrm{PCDH} 10$ methylation $(\mathrm{P}=0.006)$ were associated 
Table III. Association between PCDH10 methylation and different clinicopathological parameters.

\begin{tabular}{|c|c|c|c|c|c|c|c|}
\hline \multirow[b]{2}{*}{ Variables } & \multirow[b]{2}{*}{ Total, $\mathrm{n}$} & \multicolumn{2}{|c|}{$\begin{array}{l}\text { Unmethylated } \\
\text { PCDH10 }\end{array}$} & \multicolumn{2}{|c|}{$\begin{array}{l}\text { Methylated } \\
\text { PCDH10 }\end{array}$} & \multirow[b]{2}{*}{$\chi^{2}$} & \multirow[b]{2}{*}{ P-value } \\
\hline & & $\mathrm{n}$ & $\%$ & $\mathrm{n}$ & $\%$ & & \\
\hline Age (years) & & & & & & 0.798 & 0.372 \\
\hline$<45$ & 128 & 60 & 36.1 & 68 & 30.1 & & \\
\hline$\geq 45$ & 264 & 106 & 63.9 & 158 & 69.9 & & \\
\hline Grade & & & & & & 0.168 & 0.682 \\
\hline $\mathrm{I}+\mathrm{II}$ & 360 & 154 & 92.8 & 206 & 91.2 & & \\
\hline III & 32 & 12 & 7.2 & 20 & 8.8 & & \\
\hline Tumor size $(\mathrm{cm})$ & & & & & & 8.325 & $0.004^{\mathrm{a}}$ \\
\hline$<2$ & 126 & 72 & 43.4 & 54 & 23.9 & & \\
\hline$\geq 2$ & 266 & 94 & 56.6 & 172 & 76.1 & & \\
\hline LNM & & & & & & 0.040 & 0.841 \\
\hline Negative & 214 & 92 & 55.4 & 122 & 54.0 & & \\
\hline Positive & 178 & 74 & 44.6 & 104 & 46.0 & & \\
\hline ER & & & & & & 0.221 & 0.638 \\
\hline Negative & 106 & 42 & 25.3 & 64 & 28.3 & & \\
\hline Positive & 286 & 124 & 74.7 & 162 & 71.7 & & \\
\hline $\mathrm{PR}$ & & & & & & 0.950 & 0.330 \\
\hline Negative & 138 & 52 & 31.3 & 86 & 38.1 & & \\
\hline Positive & 254 & 114 & 68.7 & 140 & 61.9 & & \\
\hline HER-2 & & & & & & 2.276 & 0.131 \\
\hline Negative & 280 & 128 & 77.1 & 152 & 67.3 & & \\
\hline Positive & 112 & 38 & 22.9 & 74 & 32.7 & & \\
\hline P53 & & & & & & 0.285 & 0.594 \\
\hline Negative & 324 & 140 & 84.3 & 184 & 81.4 & & \\
\hline Positive & 68 & 26 & 15.7 & 42 & 18.6 & & \\
\hline Ki-67 & & & & & & 0.791 & 0.374 \\
\hline$<20 \%$ & 198 & 90 & 54.2 & 108 & 47.8 & & \\
\hline$\geq 20 \%$ & 194 & 76 & 45.8 & 118 & 52.2 & & \\
\hline Molecular subtype & & & & & & 3.399 & 0.334 \\
\hline Luminal A & 226 & 102 & 61.4 & 124 & 54.9 & & \\
\hline Luminal B & 64 & 24 & 14.5 & 40 & 17.7 & & \\
\hline HER-2 & 50 & 14 & 8.4 & 36 & 15.9 & & \\
\hline TNBC & 52 & 26 & 15.7 & 26 & 11.5 & & \\
\hline
\end{tabular}

${ }^{a} \mathrm{P}<0.05$. PCDH10, Protocadherin-10; LNM, lymph node metastasis; ER, estrogen receptor; PR, progesterone receptor; TNBC, triple-negative breast cancer; HER-2, human epidermal growth factor receptor 2; P53, tumor protein P53; n, number; Ki-67, antigen Ki-67.

with OS rate, while other factors were not associated with OS rate. Multivariate analysis revealed that tumor size $(\mathrm{P}<0.001)$, LNM $(\mathrm{P}<0.001)$ and PCDH10 methylation $(\mathrm{P}=0.012)$ were independent predictors of prognosis (Table IV).

The results of the present study demonstrated that the frequency of gene methylation was significantly increased in breast cancer tissues compared with control. Methylation was investigated as a possible diagnostic predictor of breast cancer. Identical specific probes were used to assess PCDH10 methylation in matched serum samples using MethyLight. Samples included 300 age-matched healthy controls and
300 age-matched patients with benign breast diseases. ROC analysis of PCDH10 indicated a sensitivity of $75 \%$, a specificity of $62.5 \%$, and an area under the curve of 0.682 (95\% confidence interval; 0.645-0.719; $\mathrm{P}<0.001$; Fig. 5).

\section{Discussion}

Detection of hypermethylation is an important tool in the diagnosis of cancer and in prognostic and therapeutic guidance $(23,50,51)$. Cadherins, which serve a crucial role in cellular adhesion, are involved in tumorigenesis and progression (52). 
Table IV. Cox proportional hazards assessment of prognostic factors.

\begin{tabular}{|c|c|c|c|c|c|c|}
\hline \multirow[b]{2}{*}{ Variables } & \multicolumn{3}{|c|}{ Univariate analysis } & \multicolumn{3}{|c|}{ Multivariate analysis } \\
\hline & HR & $95 \% \mathrm{CI}$ & P-value & $\mathrm{HR}$ & $95 \% \mathrm{CI}$ & P-value \\
\hline Age ( $\geq 45$ vs. $<45$ years) & 0.879 & $(0.544-1.416)$ & 0.591 & & & \\
\hline Grade (III vs. II+I) & 0.732 & $(0.282-1.780)$ & 0.482 & & & \\
\hline Tumor size ( $\geq 2$ vs. $<2 \mathrm{~cm}$ ) & 3.712 & $(2.039-7.569)$ & $<0.00^{\mathrm{a}}$ & 3.115 & $(1.597-6.274)$ & $<0.00^{\mathrm{a}}$ \\
\hline LNM (positive vs. negative) & 2.531 & $(1.903-4.181)$ & $<0.001^{\mathrm{a}}$ & 2.337 & $(1.939-3.842)$ & $<0.001^{\mathrm{a}}$ \\
\hline ER (positive vs. negative) & 0.682 & $(0.464-0.929)$ & $0.026^{\mathrm{a}}$ & & & \\
\hline PR (positive vs. negative) & 0.744 & $(0.539-1.197)$ & 0.127 & & & \\
\hline Her2 (positive vs. negative) & 1.547 & $(0.983-2.119)$ & 0.115 & & & \\
\hline p53 (positive vs. negative) & 1.411 & $(0.886-2.124)$ & 0.298 & & & \\
\hline Ki-67 (positive vs. negative) & 1.269 & $(0.846-1.692)$ & 0.534 & & & \\
\hline PCDH10 (methylated vs. unmethylated) & 1.780 & $(1.322-3.117)$ & $0.006^{\mathrm{a}}$ & 1.798 & $(1.231-3.071)$ & $0.011^{\mathrm{a}}$ \\
\hline
\end{tabular}

${ }^{\mathrm{a}} \mathrm{P}<0.05$. CI, confidence interval; HR, hazard ratio; PCDH10, Protocadherin-10; LNM, lymph node metastasis; ER, estrogen receptor; PR, progesterone receptor; TNBC, triple-negative breast cancer; HER-2, human epidermal growth factor receptor 2; P53, tumor protein P53; Ki-67, antigen Ki-67.

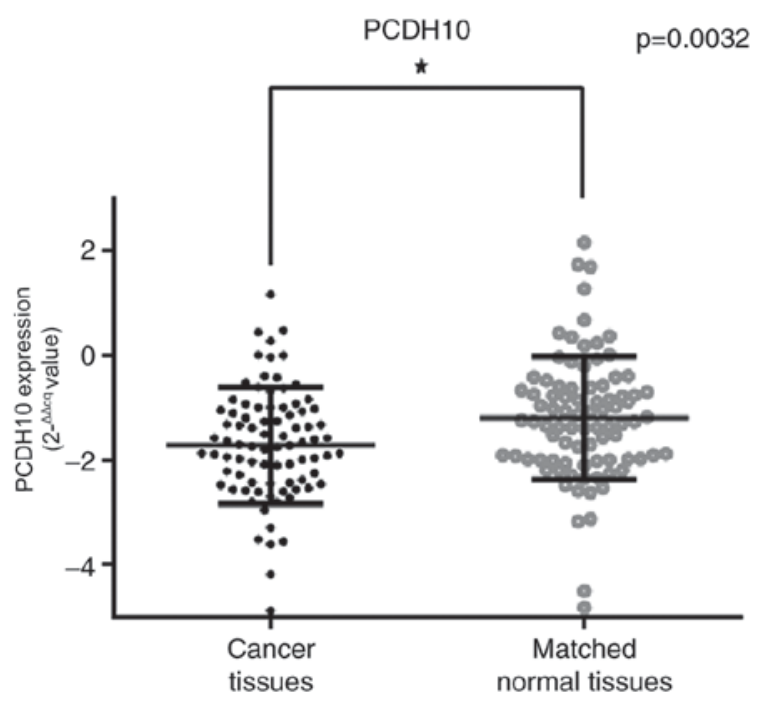

Figure 3. PCDH10 mRNA expression in breast cancer tissues and matched normal breast tissues. ${ }^{*} \mathrm{P}<0.05$. PCDH10, Protocadherin-10; mRNA, microRNA.

There are three primary types of cadherin: Classical cadherins, desmosomal cadherins and PCDHs. E-cadherin has been reported to act as a tumor suppressor and to participate in carcinogenesis, particularly in breast and gastric cancer (53). PCDHs constitute one of the largest subgroups of the cadherin superfamily. Previous studies have indicated that various types of cancer are associated with abnormal promoter methylation of cadherin family genes (54). It has been reported that the expression of PCDH is dependent on epigenetic modifications (55). In addition, promoter methylation has been indicated to trigger inactivation of PCDH-17/20 in various types of cancer. Therefore, aberrant promoter methylation may be a competent diagnostic and prognostic biomarker for cancer (55-57).

It has been reported that PCDH10 suppresses proliferation, metastasis and invasion of cancer cells (58-60). Promoter methylation and transcriptional silencing of PCDH1 has

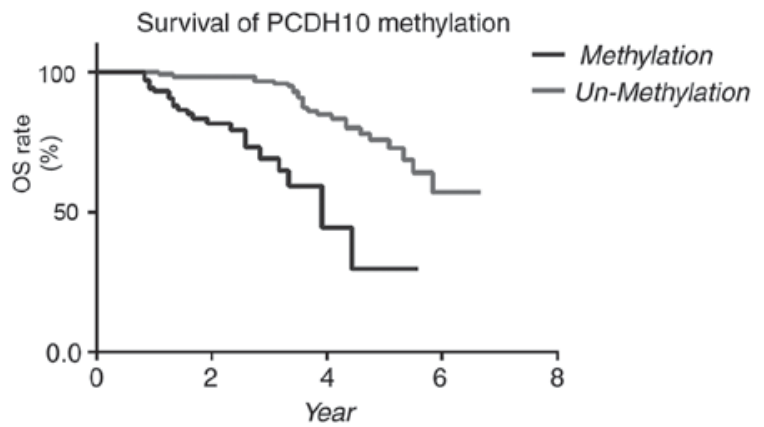

Figure 4. Kaplan-Meier survival curves of the overall survival rate of patients with methylated and unmethylated PCDH10. PCDH10, Protocadherin-10; OS, overall survival.

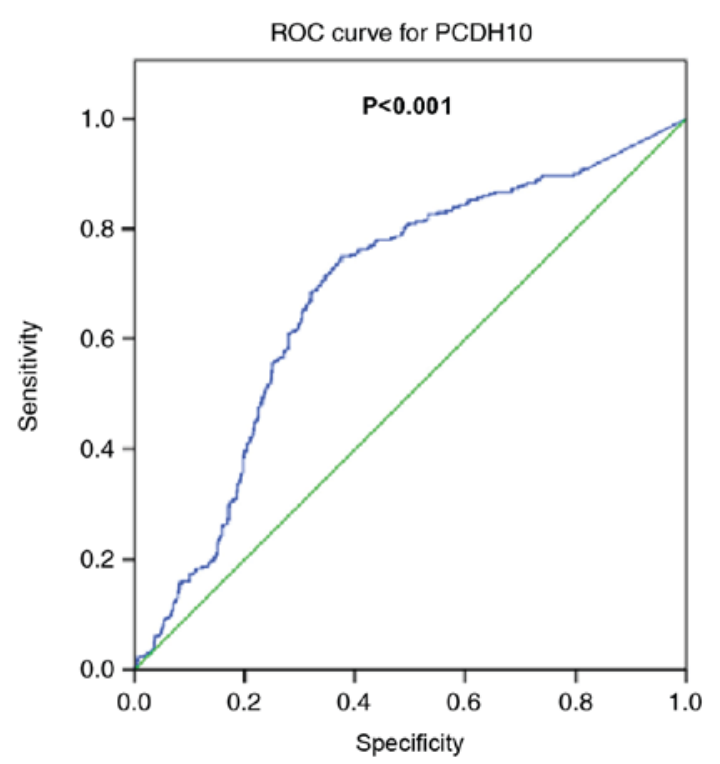

Figure 5. Receiver operating characteristic analysis of PCDH10 expression in breast cancer tissues. PCDH10, Protocadherin-10; ROC, receiver operating characteristic. 
been reported in various types of cancer, including myeloma, nasopharyngeal, esophageal, colorectal, cervical, lung and hepatocellular carcinoma cell lines (26,61-64). As the present study demonstrated, silencing of PCDH10 methylation also occurs in breast cancer cells.

MethyLight was used in the present study to identify hypermethylation-silenced genes in tumor tissues. These genes may be candidate tumor suppressor genes (TSGs). PCDH10 is frequently silenced by methylation in a tumor-specific manner (26). The results of the present study suggest that PCDH10 serves a critical role in cancer suppression, and that PCDH10 silencing is associated with tumor growth and progression. In addition, PCDH10 participates in nervous system development (26), and functions as a TSG in various types of cancer. Numerous studies have reported that the frequency of methylation significantly increases with cancer progression, and that methylation may be a potential prognostic predictor in breast cancer $(47,65)$.

Breast cancer tissues and paired healthy tissues were examined and PCDH10 methylation was identified in $~ 72 \%$ of breast cancer tissues. It was also determined that the rate of low PCDH10 expression rate was $\sim 70 \%$. DNA methylation can silence TSGs and, therefore, we hypothesized that decreased PCDH10 expression may be attributed to its methylation. Using a large sample size, it was concluded that PCDH10 methylation occurs in the majority of breast cancer cases. The present study demonstrated that PCDH10 methylation is associated with tumor size $(\mathrm{P}=0.004)$. In the tumor size $\geq 2 \mathrm{~cm}$ group, methylated PCDH10 tissues were more prevalent than unmethylated PCDH10 tissues. This indicates that DNA methylation may serve an important role in breast cancer. The present study, to the best of our knowledge, is the first to investigate the prognostic value of PCDH10 gene promoter methylation in patients with breast cancer. Patients with PCDH10 methylation exhibited notably reduced OS rates compared with patients exhibiting unmethylated PCDH10 ( $\mathrm{P}=0.005$, log-rank test). Therefore, $\mathrm{PCDH} 10$ methylation is indicated to be independently associated with poor prognosis in patients with invasive breast cancer. The present study is the first, to the best of our knowledge, to illustrate the association between DNA methylation, clinicopathological characteristics and survival in Chinese patients with breast cancer.

Furthermore, cell-free DNA detected in serum and extracted from cancer cells has been used as a non-invasive biomarker to facilitate diagnosis and prognostic guidance for various types of cancer, including gastric cancer $(66,67)$. Another study also detected PCDH10 methylation in serum, providing further evidence of clinical relevance in other types of cancer, including prostate cancer (68). Methylation detection has the potential to improve the existing understanding of the development of cancer, including tumor differentiation, stage and distant metastasis.

In conclusion, the results of the present study suggest that frequency of PCDH10 promoter methylation is increased in human breast cancer tissues, compared with adjacent non-tumor tissues. PCDH10 was concluded to be an important TSG, which restricted the progression of breast cancer. In addition, the methylation status of PCDH10 may be a useful diagnostic and prognostic biomarker for breast cancer. However, it has been reported that environmental and lifestyle factors can alter the status of DNA methylation $(69,70)$. The present study did not exclude the effects of smoking and alcohol intake on methylation, and therefore, further investigation is required to consider this factor.

\section{Acknowledgements}

Not applicable.

\section{Funding}

Not applicable.

\section{Availability of data and materials}

The data used and analyzed during the current study are available from the corresponding author on reasonable request.

\section{Authors' contributions}

QZ designed the study and revised the paper. WL and JW performed the studies. GS, XY and DL performed the statistical analysis. All authors read and approved the final manuscript.

\section{Ethics approval and consent to participate}

This research was completed in compliance with the Helsinki Declaration. The data collection and analysis were conducted without disclosing patients' identities. All patients provided written informed consent for tissue and serum collection, in consistence with regulations of the institutional review board of the Harbin Medical University (Heilongjiang, China).

\section{Patient consent for publication}

All patients provided written informed consent for publication, in consistence with regulations of the institutional review board of the Harbin Medical University (Heilongjiang, China).

\section{Competing interests}

The authors declare that they have no competing interests.

\section{References}

1. Seneviratne S, Lawrenson R, Scott N, Kim B, Shirley R and Campbell I: Breast cancer biology and ethnic disparities in breast cancer mortality in new zealand: A cohort study. PLoS One 10: e0123523, 2015.

2. DeSantis C, Ma J, Bryan L and Jemal A: Breast cancer statistics, 2013. CA Cancer J Clin 64: 52-62, 2014.

3. Fan L, Strasser-Weippl K, Li JJ, St Louis J, Finkelstein DM, Yu KD, Chen WQ, Shao ZM and Goss PE: Breast cancer in China. Lancet Oncol 15: e279-89, 2014.

4. Frazer KA, Murray SS, Schork NJ and Topol EJ: Human genetic variation and its contribution to complex traits. Nat Rev Genet 10: 241-251, 2009.

5. Rivera CM and Ren B: Mapping human epigenomes. Cell 155: 39-55, 2013.

6. Maurano MT, Humbert R, Rynes E, Thurman RE, Haugen E, Wang H, Reynolds AP, Sandstrom R, Qu H, Brody J, et al: Systematic localization of common disease-associated variation in regulatory DNA. Science 337: 1190-1195, 2012. 
7. Baylin SB and Ohm JE: Epigenetic gene silencing in cancer-a mechanism for early oncogenic pathway addiction? Nat Rev Cancer 6: 107-116, 2006.

8. Feinberg AP, Ohlsson R and Henikoff S: The epigenetic progenitor origin of human cancer. Nat Rev Genet 7: 21-33, 2006.

9. Esteller M, Fraga MF, Guo M, Garcia-Foncillas J, Hedenfalk I, Godwin AK, Trojan J, Vaurs-Barrière C, Bignon YJ, Ramus $\mathrm{S}$, et al: DNA methylation patterns in hereditary human cancers mimic sporadic tumorigenesis. Hum Mol Genet 10: 3001-3007, 2001.

10. Craig JM and Bickmore WA: The distribution of $\mathrm{CpG}$ islands in mammalian chromosomes. Nat Genet 7: 376-382, 1994.

11. Eden A, Gaudet F, Waghmare A and Jaenisch R: Chromosomal instability and tumors promoted by DNA hypomethylation. Science 300: 455, 2003

12. Esteller M: Epigenetics in cancer. N Engl J Med 358: 1148-1159, 2008.

13. Fernandez AF, Assenov Y, Martin-Subero JI, Balint B, Siebert R, Taniguchi H, Yamamoto H, Hidalgo M, Tan AC, Galm O, et al: A DNA methylation fingerprint of 1628 human samples. Genome Res 22: 407-419, 2012.

14. Moarii M, Boeva V, Vert JP and Reyal F: Changes in correlation between promoter methylation and gene expression in cancer. BMC Genomics 16: 873, 2015.

15. Yu YY, Sun CX, Liu YK, Li Y, Wang L and Zhang W: Genome-wide screen of ovary-specific DNA methylation in polycystic ovary syndrome. Fertil Steril 104: 145-153.e6, 2015.

16. Esteller M: Cancer epigenomics: DNA methylomes and histone-modification maps. Nat Rev Genet 8: 286-298, 2007.

17. Van Neste L, Herman JG, Otto G, Bigley JW, Epstein JI and Van Criekinge W: The epigenetic promise for prostate cancer diagnosis. Prostate 72: 1248-1261, 2012.

18. Lo PK and Sukumar S: Epigenomics and breast cancer. Pharmacogenomics 9: 1879-1902, 2008.

19. Shan M, Su Y, Kang W, Gao R, Li X and Zhang G: Aberrant expression and functions of protocadherins in human malignant tumors. Tumour Biol 37: 12969-12981, 2016.

20. OtaniK,LiX,Arakawa T, Chan FK and Yu J: Epigenetic-mediated tumor suppressor genes as diagnostic or prognostic biomarkers in gastric cancer. Expert Rev Mol Diagn 13: 445-455, 2013

21. Yu J, Cheng YY, Tao Q, Cheung KF, Lam CN, Geng H, Tian LW, Wong YP, Tong JH, Ying JM, et al: Methylation of protocadherin 10 , a novel tumor suppressor, is associated with poor prognosis in patients with gastric cancer. Gastroenterology 136: 640-651 e1, 2009.

22. Lv J, Zhu P, Yang Z, Li M, Zhang X, Cheng J, Chen X and Lu F: $\mathrm{PCDH} 20$ functions as a tumour-suppressor gene through antagonizing the Wnt/ $\beta$-catenin signalling pathway in hepatocellular carcinoma. J Viral Hepat 22: 201-211, 2015.

23. Zhang C, Peng Y, Yang F, Qin R, Liu W and Zhang C: PCDH8 is frequently inactivated by promoter hypermethylation in liver cancer: Diagnostic and clinical significance. J Cancer 7: 446-452, 2016.

24. Lee NK, Lee JH, Kim WK, Yun S, Youn YH, Park CH, Choi YY, Kim H and Lee SK: Promoter methylation of PCDH10 by HOTAIR regulates the progression of gastrointestinal stromal tumors. Oncotarget 7: 75307-75318, 2016 .

25. Miyamoto K, Fukutomi T, Akashi-Tanaka S, Hasegawa T, Asahara T, Sugimura T and Ushijima T: Identification of 20 genes aberrantly methylated in human breast cancers. Int J Cancer 116: 407-414, 2005

26. Ying J, Li H, Seng TJ, Langford C, Srivastava G, Tsao SW, Putti T, Murray P, Chan AT and Tao Q: Functional epigenetics identifies a protocadherin $\mathrm{PCDH} 10$ as a candidate tumor suppressor for nasopharyngeal, esophageal and multiple other carcinomas with frequent methylation. Oncogene 25 : 1070-1080, 2006.

27. Foulkes WD: Inherited susceptibility to common cancers. N Engl J Med 359: 2143-2153, 2008.

28. Pharoah PD, Day NE, Duffy S, Easton DF and Ponder BA: Family history and the risk of breast cancer: A systematic review and meta-analysis. Int J Cancer 71: 800-809, 1997.

29. Porter P: 'Westernizing' women's risks? Breast cancer in lower-income countries. N Engl J Med 358: 213-216, 2008.

30. Lynch HT, Silva E, Snyder C and Lynch JF: Hereditary breast cancer: Part I. Diagnosing hereditary breast cancer syndromes. Breast J 14: 3-13, 2008

31. Majdak-Paredes EJ and Fatah F: Hereditary breast cancer syndromes and clinical implications. J Plast Reconstr Aesthet Surg 62: 181-189, 2009.
32. Harvey JM, Clark GM, Osborne CK and Allred DC: Estrogen receptor status by immunohistochemistry is superior to the ligand-binding assay for predicting response to adjuvant endocrine therapy in breast cancer. J Clin Oncol 17: 1474-1481, 1999.

33. Ogura H, Akiyama F, Kasumi F, Kazui T and Sakamoto G: Evaluation of HER-2 status in breast carcinoma by fluorescence in situ hybridization and immunohistochemistry. Breast Cancer 10: 234-240, 2003.

34. Soong R, Robbins PD, Dix BR, Grieu F, Lim B, Knowles S, Williams KE, Turbett GR, House AK and Iacopetta BJ: Concordance between $\mathrm{p} 53$ protein overexpression and gene mutation in a large series of common human carcinomas. Hum Pathol 27: 1050-1055, 1996.

35. Hugh J, Hanson J, Cheang MC, Nielsen TO, Perou CM, Dumontet C, Reed J, Krajewska M, Treilleux I, Rupin M, et al: Breast cancer subtypes and response to docetaxel in node-positive breast cancer: Use of an immunohistochemical definition in the BCIRG 001 trial. J Clin Oncol 27: 1168-1176, 2009.

36. Yu Y, Yan W, Liu X, Jia Y, Cao B, Yu Y, Lv Y, Brock MV, Herman JG, Licchesi J, et al: DACT2 is frequently methylated in human gastric cancer and methylation of DACT2 activated Wnt signaling. Am J Cancer Res 4: 710-724, 2014.

37. Koontz L: Agarose gel electrophoresis. Methods Enzymol 529: 35-45, 2013.

38. Livak KJ and Schmittgen TD: Analysis of relative gene expression data using real-time quantitative PCR and the 2(-Delta Delta C(T)) method. Methods 25: 402-408, 2001.

39. Eads CA, Danenberg KD, Kawakami K, Saltz LB, Blake C, Shibata D, Danenberg PV and Laird PW: MethyLight: A high-throughput assay to measure DNA methylation. Nucleic Acids Res 28: E32, 2000.

40. Kagan J, Srivastava S, Barker PE, Belinsky SA and Cairns P: Towards clinical application of methylated DNA sequences as cancer biomarkers: A Joint NCI's EDRN and NIST workshop on standards, methods, assays, reagents and tools. Cancer Res 67: 4545-4549, 2007

41. Ogino S, Kawasaki T, Brahmandam M, Cantor M, Kirkner GJ, Spiegelman D, Makrigiorgos GM, Weisenberger DJ, Laird PW, Loda $\mathrm{M}$ and Fuchs CS: Precision and performance characteristics of bisulfite conversion and real-time PCR (MethyLight) for quantitative DNA methylation analysis. J Mol Diagn 8: 209-217, 2006.

42. Widschwendter M, Siegmund KD, Müller HM, Fiegl H, Marth C, Müller-Holzner E, Jones PA and Laird PW: Association of breast cancer DNA methylation profiles with hormone receptor status and response to tamoxifen. Cancer Res 64: 3807-3813, 2004.

43. Widschwendter M, Apostolidou S, Jones AA, Fourkala EO, Arora R, Pearce CL, Frasco MA, Ayhan A, Zikan M, Cibula D, et al: HOXA methylation in normal endometrium from premenopausal women is associated with the presence of ovarian cancer: A proof of principle study. Int J Cancer 125: 2214-2218, 2009.

44. Cho YH, Shen J, Gammon MD, Zhang YJ, Wang Q, Gonzalez K, Xu X, Bradshaw PT, Teitelbaum SL, Garbowski G, et al: Prognostic significance of gene-specific promoter hypermethylation in breast cancer patients. Breast Cancer Res Treat 131: 197-205, 2012

45. Wang W and Srivastava S: Strategic approach to validating methylated genes as biomarkers for breast cancer. Cancer Prev Res (Phila) 3: 16-24, 2010.

46. Clark SJ and Melki J: DNA methylation and gene silencing in cancer: Which is the guilty party? Oncogene 21: 5380-5387, 2002.

47. Muggerud AA, Rønneberg JA, Wärnberg F, Botling J, Busato F, Jovanovic J, Solvang H, Bukholm I, Børresen-Dale AL, Kristensen VN, et al: Frequent aberrant DNA methylation of ABCB1, FOXC1, PPP2R2B and PTEN in ductal carcinoma in situ and early invasive breast cancer. Breast Cancer Res 12: R3, 2010.

48. Wolverton $\mathrm{T}$ and Lalande M: Identification and characterization of three members of a novel subclass of protocadherins. Genomics 76: 66-72, 2001.

49. Qiu GH, Tan LK, Loh KS, Lim CY, Srivastava G, Tsai ST, Tsao SW and Tao Q: The candidate tumor suppressor gene BLU, located at the commonly deleted region 3p21.3, is an E2F-regulated, stress-responsive gene and inactivated by both epigenetic and genetic mechanisms in nasopharyngeal carcinoma. Oncogene 23: 4793-4806, 2004. 
50. Jeschke J, Van Neste L, Glöckner SC, Dhir M, Calmon MF, Deregowski V, Van Criekinge W, Vlassenbroeck I, Koch A, Chan TA, et al: Biomarkers for detection and prognosis of breast cancer identified by a functional hypermethylome screen. Epigenetics 7: 701-709, 2012

51. Morris MR, Ricketts C, Gentle D, Abdulrahman M, Clarke N, Brown M, Kishida T, Yao M, Latif F and Maher ER: Identification of candidate tumour suppressor genes frequently methylated in renal cell carcinoma. Oncogene 29: 2104-2117, 2010.

52. Mendonsa AM, Na TY and Gumbiner BM: E-cadherin in contact inhibition and cancer. Oncogene, 2018.

53. Su YJ, Chang YW, Lin WH, Liang CL and Lee JL: An aberrant nuclear localization of E-cadherin is a potent inhibitor of Wnt/beta-catenin-elicited promotion of the cancer stem cell phenotype. Oncogenesis 4: e157, 2015.

54. Patra SK and Bettuzzi S: Epigenetic DNA-methylation regulation of genes coding for lipid raft-associated components: A role for raft proteins in cell transformation and cancer progression (review). Oncol Rep 17: 1279-1290, 2007.

55. Imoto I, Izumi H, Yokoi S, Hosoda H, Shibata T, Hosoda F, Ohki M, Hirohashi S and Inazawa J: Frequent silencing of the candidate tumor suppressor PCDH20 by epigenetic mechanism in non-small-cell lung cancers. Cancer Res 66: 4617-4626, 2006.

56. Haruki S, Imoto I, Kozaki K, Matsui T, Kawachi H, Komatsu S, Muramatsu T, Shimada Y, Kawano T and Inazawa J: Frequent silencing of protocadherin 17, a candidate tumour suppressor for esophageal squamous cell carcinoma. Carcinogenesis 31: $1027-1036,2010$

57. Uyen TN, Sakashita K, Al-Kzayer LF, Nakazawa Y, Kurata T and Koike K: Aberrant methylation of protocadherin 17 and its prognostic value in pediatric acute lymphoblastic leukemia. Pediatr Blood Cancer 64, 2017.

58. Qiu C,Bu X and Jiang Z: Protocadherin-10 acts as a tumor suppressor gene, and is frequently downregulated by promoter methylation in pancreatic cancer cells. Oncol Rep 36: 383-389, 2016.

59. Shi D, Murty VV and Gu W: PCDH10, a novel p53 transcriptional target in regulating cell migration. Cell Cycle 14: 857-866, 2015

60. Yang Y, Jiang Y, Jiang M, Zhang J, Yang B, She Y, Wang W, Deng Y and Ye Y: Protocadherin 10 inhibits cell proliferation and induces apoptosis via regulation of DEP domain containing 1 in endometrial endometrioid carcinoma. Exp Mol Pathol 100: 344-352, 2016

61. Wang KH, Liu HW, Lin SR, Ding DC and Chu TY: Field methylation silencing of the protocadherin 10 gene in cervical carcinogenesis as a potential specific diagnostic test from cervical scrapings. Cancer Sci 100: 2175-2180, 2009.
62. Tang X, Yin X, Xiang T, Li H, Li F, Chen L and Ren G: Protocadherin 10 is frequently downregulated by promoter methylation and functions as a tumor suppressor gene in non-small cell lung cancer. Cancer Biomark 12: 11-19, 2013.

63. Li Y, Yang ZS, Song JJ, Liu Q and Chen JB: Protocadherin-10 is involved in angiogenesis and methylation correlated with multiple myeloma. Int J Mol Med 29: 704-710, 2012.

64. Zhong X, Zhu Y, Mao J, Zhang J and Zheng S: Frequent epigenetic silencing of PCDH10 by methylation in human colorectal cancer. J Cancer Res Clin Oncol 139: 485-490, 2013.

65. Novak P, Jensen TJ, Garbe JC, Stampfer MR and Futscher BW Stepwise DNA methylation changes are linked to escape from defined proliferation barriers and mammary epithelial cell immortalization. Cancer Res 69: 5251-5258, 2009.

66. Pimson C, Ekalaksananan T, Pientong C, Promthet S, Putthanachote N, Suwanrungruang K and Wiangnon S: Aberrant methylation of PCDH10 and RASSF1A genes in blood samples for non-invasive diagnosis and prognostic assessment of gastric cancer. Peer J 4: e2112, 2016

67. Hou YC, Deng JY, Zhang RP, Xie XM, Cui JL, Wu WP, Hao XS and Liang H: Evaluating the clinical feasibility: The direct bisulfite genomic sequencing for examination of methylated status of protocadherin10 (PCDH10) promoter to predict the prognosis of gastric cancer. Cancer Biomark 15: 567-573, 2015.

68. Deng QK, Lei YG, Lin YL, Ma JG and Li WP: Prognostic value of Protocadherin10 (PCDH10) methylation in serum of prostate cancer patients. Med Sci Monit 22: 516-521, 2016.

69. Donkin I and Barres R: Sperm epigenetics and influence of environmental factors. Mol Metab: Feb 27, 2018 (Epub ahead of print).

70. Ingerslev LR, Donkin I, Fabre O, Versteyhe S, Mechta M, Pattamaprapanont P, Mortensen B, Krarup NT and Barrès R: Endurance training remodels sperm-borne small RNA expression and methylation at neurological gene hotspots. Clin Epigenetics 10: 12, 2018. International (CC BY-NC-ND 4.0) License. 